\title{
Una critica a la teoría de la acción comunicativa habermasiana desde las tesis postoperaistas
}

\author{
Antonio Gómez Villar \\ Universitat de Barcelona \\ antonio.gomez.villar@hotmail.com \\ https://orcid.org/0000-0002-6433-4945
}

\begin{abstract}
Resumen: En este artículo revisamos la crítica postoperaista a la teoría de la acción comunicativa de Jürgen Habermas a la luz de los problemas políticos abiertos por el régimen de producción postfordista. Atenderemos a la lectura postoperaista y habermasiana de los Grundrisse de Marx, prestando especial atención al concepto de trabajo vivo; analizaremos en qué medida el potencial hermenéutico de la acción comunicativa queda anulado por el desplazamiento del problema del nivel ontológico al ético; y argumentaremos que la dualidad entre trabajo material y trabajo inmaterial presentada por el postoperaismo no reproduce el dualismo habermasiano entre acción comunicativa y acción instrumental.
\end{abstract}

Palabras clave: Habermas; postoperaismo; postfordismo; Negri; Virno

\begin{abstract}
A Critique of the Habermassian Theory of Communicative Action viewed through the Prism of the Post-operaist Theses". This article revisits the postoperaist critique of Jürgen Habermas's Theory of communicative action in light of the political issues prompted by the post-Fordist production system. It examines the post-operaist and Habermassian interpretation of Marx's Grundrisse, focusing in particular on the concept of living labor. We also analyze the extent to which the hermeneutic potential of communicative action is annulled by shifting the problem from the ontological level to the ethical realm. Lastly, we argue that the duality between material labor and immaterial labor presented by post-operaism does not replicate the habermassian duality between communicative action and instrumental action.
\end{abstract}

Keywords: Habermas; post-operaist; post-Fordist; Negri; Virno 
1. El lugar del lenguaje en la "racionalidad comunicativa" habermasiana y en el tránsito del "obrero masa" al "obrero social"

Plantear una confrontación entre Habermas y el postoperaismo italiano no es una tarea fácil, no solo por las enormes distancias teóricas existentes entre las dos tradiciones filosóficas, sino también porque apenas existen referencias reciprocas. Del lado postoperaista, las reflexiones en torno a Habermas son apresuradas, cuando no desechadas sin mayor consideración. Solo en la obra El poder constituyente de Antonio Negri encontramos una reflexión algo más pausada, pero no nos detendremos en ella porque las discusiones allí planteadas exceden los objetivos de este artículo; del lado de Habermas, solo encontramos un rechazo frontal de la propuesta filosófica de Negri, a la que considera una visión excesivamente especulativa que no ofrece ninguna contribución ni diagnóstico valioso para pensar el futuro del derecho internacional.

Las críticas de los autores postoperaistas (nos referiremos a tres, Antonio Negri, Paolo Virno y Christian Marazzi) deben ser inscritas en sus análisis sobre las fuertes transformaciones acaecidas en el mundo del trabajo desde los años 70 del pasado siglo, que suponen el tránsito del obrero masa al obrero social ${ }^{1}$. El obrero masa es conceptualizado como el obrero de la gran industria, siendo la fábrica el lugar privilegiado como espacio de las principales luchas. Se caracteriza por ser un trabajador que se convierte en prótesis de la máquina, en oposición a la figura del obrero profesional, del trabajador artesanal independiente, que se corresponde con la época de la manufactura: "desde la perspectiva de los procesos de trabajo, el obrero masa es una figura obrera que, por primera vez de manera global, es introducido dentro de lo que Negri llama el mando de la maquinaria"2.

Los años 70 suponen el fin de la figura del obrero masa, tanto en términos de organización capitalista del trabajo como en términos de su hegemonía política y cultural. La figura que emerge en el tránsito de la sociedad fordista a la fábrica-social es el obrero social. La conceptualización de esta figura cons-

\footnotetext{
1 Negri, A., Del obrero-masa al obrero social. Entrevista sobre el obrerismo a cargo de Paolo Pozzi y Roberta Tommasini, Barcelona: Anagrama, 1980.

2 Revelli, M., Más allá del siglo XX. La politica, las ideologías y las asechanzas del trabajo, Barcelona: El Viejo Topo, 2002, p. 123. Énfasis añadido.
} 
tituyó el aporte sustantivo de Toni Negri en aquella época ${ }^{3}$. Si el obrero masa correspondía a una fase marcada por una concepción de la centralidad de la fábrica como espacio de luchas, con el obrero social las luchas se extienden al conjunto de la sociedad.

Si el proceso de recomposición de clase del obrero masa había sido analizado dentro de la esfera del trabajo industrial; el proceso de recomposición del obrero social va a afectar no solo al conjunto de la sociedad, la fábrica-social, sino que se extiende a todas las actividades genéricamente humanas: el lenguaje como la forma general del trabajo productivo postfordista.

Esta ampliación del campo del análisis, que marca el tránsito del obrero masa al obrero social, es, quizás, la intuición política fundamental que contribuye a redefinir el campo conceptual de recomposición de clase: un tránsito que ha producido nuevas subjetividades y ha definido nuevas relaciones culturales y políticas.

Como resultado de esta nueva configuración productiva, las relaciones de explotación capitalista se expanden por todas partes, tienden a ocupar todo el terreno social y ya no se limitan a la fábrica. Si el trabajo productivo ya no es aquel que produce directamente el capital, sino el que reproduce la sociedad, entonces la separación entre trabajo productivo y trabajo improductivo resulta completamente dislocada; la producción se halla subsumida en la circulación, en un grado cada vez mayor.

Lo que nos interesa destacar de esta transición del obrero masa al obrero social, paralelo al paso del fordismo al postfordismo, es que en el centro de estas transformaciones se encuentra la irrupción del lenguaje: la comunicación se ha convertido en la forma en la cual la riqueza se organiza. El papel de la comunicación en la innovación tecnológico-productiva se ha convertido en la característica fundamental para explicar las transformaciones socioeconómicas y políticas.

Así, el giro lingüístico del nuevo modo de acumulación capitalista revela para el postoperaismo que la producción de conocimiento se ha convertido en un factor interno a la exigencia capitalista de explotación. Decir que el capitalismo adopta un giro lingüístico es lo mismo que decir que la comunicación se torna parte central del proceso de valorización. El trabajo deviene lingüístico en la medida en que la comunicación se transforma en mercancía; y el intelecto,

3 Negri, A., Del obrero-masa al obrero social. Entrevista sobre el obrerismo a cargo de Paolo Pozzi y Roberta Tommasini. 
entendido como conjunto de facultades comunicativas, expresivas e inventivas, se transforma en el nuevo utensilio de la producción postfordista.

El devenir lingüístico de la producción incide directamente sobre las propias formas del trabajo, sobre los procesos de organización que lo acometen y sobre el contenido de la prestación laboral. Desde este punto de vista cualitativo, se puede decir que el trabajo se transforma cada vez más en cognitivo e inmaterial, en la medida en que se sustenta sobre la elaboración de símbolos, la construcción de lenguajes y la gestión de signos.

Si esta es la centralidad otorgada por el postoperaismo italiano al lenguaje, en tanto que elemento central para analizar el tránsito del fordismo al postfordismo, la importancia que Habermas otorga al lenguaje discurre por caminos bien distintos.

Lo que Habermas nos presenta en su la teoría de la democracia discursiva es que gracias al lenguaje podemos ir más allá de lo meramente técnicoinstrumental ${ }^{4}$. El filósofo alemán hace depender la posibilidad de una búsqueda consensual de la verdad de la mediación lingüística, porque el lenguaje que usamos tiene una racionalidad sustancial, esto es, una racionalidad que es común todos los seres humanos ${ }^{5}$. Al respecto, Marazzi señala que "la teoría de Habermas encuentra su fuerza en la pragmaticidad, en el hecho de definir la comunicación lingüística por lo que esta es en una comunidad sociopolítica dada"6.

Es por ello que la idea de democracia que propone Habermas se sostiene sobre la deliberación pública, sobre la creación de una esfera pública, entendida como un espacio intermedio entre las instituciones y la sociedad, una zona de elaboración de argumentos y deliberación ${ }^{7}$. Tal es el suelo que hace posible la democracia, porque en ella todas las decisiones se cargan de valor y significación sobre la base de la transformación que sigue a la deliberación y a la consecuencia de un consenso racional. Es la acción comunicativa, entendida como la facultad de apelar a la mediación discursiva, la que permite hacer referencia a los intereses y necesidades colectivas.

Así, la legitimación se inscribe en la determinación de las condiciones formales para la elaboración comunicativa de un consenso racional. Esta recons-

4 Habermas, J., Teoría de la acción comunicativa, Barcelona: Taurus, 1981.

5 Habermas, J., Sobre la verdad: ¿validez universal o justificación?, Buenos Aires: Amorrortu, 2008 .

6 Marazzi, Ch., El sitio de los calcetines. El giro lingüistico de la economía y sus efectos sobre la politica, Madrid: Akal, 2003, p. 24.

Habermas, J., Historia y estructura de la vida pública, Barcelona: Gustavo Gili, 2004. 
trucción racional del lenguaje se impone en la medida en que es el entendimiento y no la razón el núcleo normativo del discurso. El entendimiento tiene como base el telos del lenguaje, apoyado en las pretensiones de validez del habla; y el discurso, por su parte, es el medio racional del entendimiento y cuya validez radica en la fuerza del mejor argumento.

La definición de este consenso racional es puramente procedimental, formal, definido a partir de las ideas de simetría, igualdad, libertad y autonomía entre las partes que de manera contrafáctica, a partir de una construcción heurística, posibilita la situación ideal de diálogo. Esta situación ideal exige la presunción de racionalidad, esto es, describe las condiciones de posibilidad de la racionalidad; y constituye la condición necesaria para una argumentación racional. Por lo que solo el diálogo permite una reconstrucción normativa de la legitimación a partir de una comunicación libre, sin coacciones externas. Es así como logramos la formación discursiva de una voluntad colectiva, razón por la cual la democracia se fundamenta normativamente en un principio consensual de legitimación. Es, pues, la democracia discursiva la que determina las condiciones de posibilidad de una racionalidad comunicativa democrática.

La democracia discursiva habermasiana está pensada desde las sociedades regidas por sistemas democráticos liberales, siendo el lenguaje la mediación que permite comunicarse a los ciudadanos. Esa libertad, inherente a todo sistema liberal, necesita de reglas gramaticales, mediaciones lingüisticas, que posibiliten construir el marco mismo del conflicto democrático ${ }^{9}$. Así pues, la teoría de la democracia discursiva trata de dar respuesta al problema de las reglas necesarias para el gobierno de la democracia.

Por ello, la opinión pública es concebida por Habermas en términos de acción comunicativa encaminada a alcanzar un entendimiento y conformar un marco de valores. Esta esfera pública es democrática en la medida que permite la libre expresión y la pluralidad de los intercambios comunicativos ${ }^{10}$. Habermas propone esta esfera pública como alternativa a la razón instrumental y al control capitalista de la comunicación.

Se entiende, entonces, por qué para Habermas adquiere una vital importancia el lenguaje, en la medida que "el lenguaje que se dirige al entendimiento constituye el modo original de utilización del lenguaje respecto del cual... las

\footnotetext{
8 Habermas, J., Facticidad y Validez, Barcelona: Trotta, 1998.

9 Habermas, J., Debate sobre el liberalismo politico, Barcelona: Paidós, 1998.

${ }^{10}$ Habermas, J., Normas y valores, Barcelona: Trotta, 2008.
} 
utilizaciones instrumentales son parasitarias"11. Siendo esto así, es necesario que toda discusión racional tenga pretensiones de validez, incorporando los presupuestos de la acción comunicativa: una acción simbólicamente mediada, orientada por normas consensuadas intersubjetivamente. Este es el objetivo último que persigue Habermas con su reconstrucción formal y universal del uso del lenguaje.

Es por ello que Habermas distingue entre dos formas fundamentales de la acción, la acción instrumental y la acción comunicativa, que constituyen un marco trascendental en cuyo interior organizamos la experiencia a priori de toda realidad. La acción comunicativa es aquel tipo de acción social orientada al entendimiento de los sujetos a través de un proceso dialogal de consensualización; y la acción instrumental y estratégica es aquella orientada al éxito. Con este planteamiento, Habermas trata de criticar a la tradición materialista, al tiempo que propone un concepto de razón más amplio, en el que la racionalidad comunicativa, dirigida a la comprensión, se opone a la mera racionalidad estratégica.

De esta manera según en el ámbito en el que operemos, estaremos guiados por un interés diferente de conocimiento ${ }^{12}$. Ello dibuja un territorio, el de lo público, que no puede penetrar en los espacios privados donde las palabras en él pronunciadas no tienen como objetivo una intervención política, pública. Dicho en otros términos, la teoría de la acción comunicativa es independiente de los imperativos instrumentales inherentes a la esfera económica. Con ello, allí donde comienza el espacio privado, termina y desaparece la política.

Esta razón comunicativa, que constituye para Habermas la dimensión de la razón que está presupuesta en el entendimiento lingüístico, comporta tres consecuencias: en primer lugar, una fuerte ligazón entre razón y realidad; segundo, que la realidad se construye través de la comunicación y la interacción; $\mathrm{y}$, tercero, que la razón comunicativa ha de estar estructurada de forma comunicativa, de manera que permita poder argumentar contra las ideas preconcebidas y señalar esquemas de comunicación "sistemáticamente distorsionados" 13 .

${ }^{11}$ Habermas, J., Teoría de la acción comunicativa, p. 388.

${ }^{12}$ Habermas, J., Conocimiento en interés, Valencia: Universitat de Valencia, 1995.

${ }^{13}$ Habermas, J., La ética del discurso y la cuestión de la verdad, Barcelona: Paidós, 2003. 
2. La lectura de los Grundrisse: el trabajo vivo como principio productivo inmanente

De las distintas lecturas que se realizaron de la obra de Karl Marx a partir de los años 70, el operaismo italiano centró su atención en los Grundrisse, cuyo borrador está fechado entre 1857 y 1858, en tiempos de la expansión final de la revolución industrial en Europa. En Italia, en 1968, se tradujo esta obra de Marx como Lineamenti fondamentali per la critica dell'economia politica, por Enzo Grillo. Un reducido número de páginas encontrado en el Cuaderno VI y en el inicio del Cuaderno VII de los Grundrisse, "El fragmento sobre las máquinas", constituyó el punto de partida e inspiración permanente del operaismo italiano.

A partir de mediados de la década de los 80 , el interés de la lectura postoperaista se focaliza sobre la fenomenología-sociología del trabajo intelectual, es decir, de la nueva fuerza de trabajo inmaterial que el desarrollo capitalista y la lucha de clases colocan en el centro del análisis. La nueva determinación del trabajo vivo se encuentra dada en la cuestión de la hegemonía política que remite al general intellect para una inversión revolucionaria de su concepto. Será la revista Luogo Comune la que sirva de puente con el punto de vista teórico-político de los años 70, reabriendo el debate en torno al general intellect y al sujeto político adecuado para el nivel de socialización de las fuerzas productivas: la intelectualidad de masas.

El principio de la hipótesis postoperaista acerca del trabajo inmaterial se remonta al citado "Fragmento sobre las máquinas" de los Grundrisse. En él, Marx acuña el concepto de general intellect y formula una hipótesis sobre el desenvolvimiento de la forma-trabajo en el futuro del desarrollo capitalista. El general intellect es definido como una inteligencia social, colectiva, creada por conocimientos, técnicas y saberes acumulados. Esta transformación radical de la fuerza de trabajo, y la incorporación de la ciencia, la comunicación y el lenguaje dentro de las fuerzas productivas, redefinen la totalidad de la fenomenología del trabajo y todo el horizonte de la producción.

Con el concepto general intellect, Marx hace referencia a que la forma general de la inteligencia humana se convierte en fuerza productiva en la esfera del trabajo social global y de la valorización capitalista; la actividad intelectual deviene verdadero resorte de la producción de riqueza; es el conjunto de los paradigmas epistémicos, de los lenguajes artificiales, de las constelaciones conceptuales que rigen la comunicación social y las formas de vida. 
Negri ${ }^{14}$ apunta que en los Grundrisse Marx nos dice que el desarrollo capitalista conduce a una sociedad en la cual el trabajo del obrero industrial -en cuanto trabajo inmediato- es a partir de cierto momento únicamente un elemento secundario en la organización del capitalismo. Es decir, que cuando "el capital subsume a la sociedad organizándola 'a su imagen y semejanza', el trabajo productivo deviene trabajo intelectual, cooperativo, inmaterial"15. El postfordismo vendría a ser, entonces, la realización factual de lo que en los Grundrisse tan solo constituía una tendencia.

Con el concepto general intellect, decíamos, Marx hace referencia a la ciencia y al saber de los cuales depende la productividad social. Sucede entonces que el pensamiento -además de su carácter interior que le es propio- se convierte en algo exterior, público, irrumpe en el proceso productivo. La "politización del trabajo"16 tiene lugar cuando el pensamiento se convierte en el resorte principal de la producción de riqueza. Así, Marx, con la expresión general intellect, atribuye al pensamiento un carácter exterior y, por tanto, de índole pública. Ya no se trata de un producto elaborado que posee valor -cantidad de tiempo de trabajo humano abstracto-, sino que el pensamiento en cuanto tal tiene el valor de un hecho material. En efecto, a juicio de Virno, Marx identificó el general intellect con el capital fijo, con la "capacidad científica objetivada" en el sistema de máquinas, constituyendo el eje de la producción social y siendo entendido también como 'cerebro general'.

Sin embargo, concebir el general intellect como saber objetivado en el capital fijo resulta problemático según Virno ${ }^{17}$. Y es que Marx no prestó atención al trabajo vivo: el problema radica en el hecho de que Marx concibe el general intellect como capacidad científica objetivada, como sistema de máquinas. Aun siendo este un aspecto relevante e importante, no resulta suficiente.

Dicho en otros términos, la relectura que introduce el postoperaismo del general intellect marxiano consiste en señalar que el intelecto público se identifica con la cooperación, con el actuar concertadamente del trabajo vivo, con la competencia comunicativa de los individuos. Por tanto, siempre existe una parte del general intellect que no se encarna en el sistema de máquinas,

\footnotetext{
${ }^{14}$ Negri, A., Marx más allá de Marx. Cuaderno de trabajo sobre los Grundrisse, Madrid: Akal, 2001.

15 Ibid., p. 8.

${ }^{16}$ Virno, P., Gramática de la multitud. Para un análisis de las formas de vida contemporánea, Madrid: Traficantes de sueños, 2003.

${ }^{17}$ Virno, P., Virtuosismo y revolución. La acción política en la época del desencanto, Madrid: Traficantes de sueños, 2003.
} 
sino que su manifestación tiene lugar en la actividad directa del trabajo vivo. La lengua, sostiene Virno, es pre-individual: es de todos y no es de nadie. No tenemos un "yo" individuado, sino un "se": se habla. El uso de la palabra es, pues, desde el primer momento, social, público.

En las formas de producción postfordista, conceptos tales como imaginación, creación, mentalidad, juegos lingüísticos, etcétera, no cuajan en capital fijo. Estos conceptos funcionan ellos mismos como máquinas productivas sin necesidad de "adoptar un cuerpo mecánico ni tampoco un alma electrónica"18. Por tanto, el general intellect se constituye como atributo del trabajo vivo. Ahora bien, sería un error interpretar que Virno entiende la intelectualidad de masas solo como un conjunto de funciones que poseen los trabajadores del sector terciario - de la industria cultural, del sector de la informática, investigadores, etcétera-. Con la expresión "intelectualidad de masas", Virno designa "una cualidad y un signo distintivo de toda la fuerza de trabajo social de la época postfordista, es decir, la época en la que la informatización, la comunicación juegan un papel esencial en cada repliegue del proceso de producción"19.

Negri, por su parte, arranca su reflexión desde las concepciones más básicas de la teoría biológica del lenguaje para explicar cómo a través de la facultad del lenguaje, del hecho de que hablamos, nos hacemos con nuestro cuerpo. Así, en los modos de producción postfordistas, se produce la interiorización de la máquina dentro del cuerpo biológico del individuo. No existimos fuera del lenguaje, el saber corporal es "un conjunto de conocimientos, de pasiones, de visiones, de comportamientos, de deseos, de reapropiaciones, un conjunto indestructible"20.

Por todo ello, Virno indica que el intelecto general no debe entenderse como la competencia exclusiva de un individuo, sino que el intelecto comporta una cualidad social, una fundamentación de la individuación en constante desarrollo. Para Virno, la dimensión pre-individual que reside en el habla, esto es, el pensamiento, la comunicación, se ve aumentada por el aspecto transindividual del general intellect: aunque podemos reconocer acumulaciones y sedimentaciones en el conjunto del saber acumulado por los seres humanos, no solo hemos de atender a las capacidades que son compartidas y puestas en común, sino también a la acción coordinada del trabajo vivo.

\footnotetext{
18 Ibid., p. 112

19 Ibid., p. 127.

${ }^{20}$ Negri, A., Kairos, Alma, Venus, Mutitudo, Roma: Manifestolibri, 2000, p. 67.
} 
En resumen, para los autores postoperaistas el general intellect no se acumula solamente en el capital fijo, en el sistema de máquinas, sino en las ejecuciones del cerebro social colectivo. Esta es la aportación que realizan, releyendo y, al mismo tiempo, distanciándose de Marx. Con ello, la producción ya no solo es producción de mercancías, sino de todas las condiciones dentro de las cuales se definen las subjetividades productivas. Así como para el obrero masa el capital construía condiciones salariales adecuadas, hoy para el obrero social el capital trata de construir las condiciones sociales de la comunicación. O sea, la comunicación es al obrero social lo que la relación salarial era al obrero masa ${ }^{21}$.

Habermas, por su parte, en Ciencia y tecnología como "ideología”, revisa la teoría del valor-trabajo en la formulación clásica de Karl Marx. Allí señala una deficiencia fundamental del marxismo: es una tradición que siempre redujo todas las dimensiones de la praxis humana al trabajo, por lo que siempre entendió el progreso de las sociedades humanas como el avance en el dominio técnico de la naturaleza y en el control estratégico de los seres humanos ${ }^{22}$.

Por esta razón, Habermas trata de reformular el materialismo histórico marxiano, pero no desde la teoria del valor, como hacen los postoperaistas, porque el concepto de valor marxiano y, por extensión, el de trabajo no permiten fundar una ética ${ }^{23}$. La ausencia en Habermas de una confrontación con el concepto de valor, producción y trabajo en Marx, observa Maurizio Lazzarato, es una clara influencia arendtiana ${ }^{24}$, quien transforma el concepto de trabajo marxista en un "metabolismo natural entre el hombre y la naturaleza", esto es, su reducción, en términos arendtianos, a la labor. El problema de esta lectura, de influencia arendtiana, no es de tipo filológico, no se trata de una exégesis de la teoría marxista y de una errada recepción o deformación, sino de la incapacidad de asumir la especificidad de la relación social en los términos que el capitalismo la define. Es en la transposición del concepto de trabajo de la sociedad griega a la sociedad capitalista lo que no le permite a Hannah Arendt comprender la especificidad de la relación capitalista. Y ello no solo supone una incomprensión de lo que constituye el trabajo hoy, sino también

\footnotetext{
21 Negri, A., Fin de siglo, Barcelona: Paidós, 1992, p. 114.

22 Habermas, J., Ciencia y técnica como "ideología”, Barcelona: Tecnos, 2009.

${ }^{23}$ Habermas, J., La reconstrucción del materialismo histórico, Barcelona: Taurus, 1992.

${ }^{24}$ Lazzarato, M. y otros, "Le travail: un nouveau débat pour de vieilles alternatives", en: Futur Antérieur, 35-360 (1996/2).
} 
una incomprensión del concepto de acción, igualmente separado de la especificidad de la relación capitalista.

Desde esta perspectiva, Habermas presenta un concepto muy estrecho de trabajo, limitado a la relación instrumental. Al respecto, H.J. Krahl ${ }^{25}$ ha atendido a este punto decisivo de la metodología marxista: ahí donde para Arendt y Habermas solo existe actividad humana, Marx en cambio encuentra la forma moderna de producción de subjetividad. La lectura de la metodología marxista de Krahl sostiene que las categorias de Marx capturan simultáneamente la objetividad de la producción y la subjetividad de los agentes de transformación.

Krahl reconoce que las reflexiones de Arendt y Habermas parten señalando una debilidad de la teoría marxiana: la ausencia de mediaciones en el proceso de constitución del sujeto. Sin embargo, el problema radica en la solución que propone a la carencia observada: la integración del lenguaje y de la comunicación no puede realizarse en un espacio escindido, separando así el trabajo de la acción o la acción instrumental de la acción comunicativa, debido a que es esa separación la que imposibilita captar la especificidad de la relación social capitalista.

Así pues, contrario al planteamiento de Habermas, para el postoperaismo en Marx la heteronomía y la autonomía, la libertad y la explotación, la subjetividad y la objetividad se dan al mismo tiempo dentro de la organización capitalista del trabajo. La lectura que realizan los autores postoperaistas en los años 60 y 70, a partir de la lectura de los Grundrisse, se basa en señalar cómo Marx sitúa la relación intersubjetiva en el interior de la producción capitalista, en el concepto de trabajo vivo. Y desarrollan una lectura del trabajo vivo de Marx como principio productivo inmanente, como poder ontológico que produce un aumento del ser. Tratan de llevar hasta sus últimas consecuencias el concepto de trabajo vivo como una fuerza ontológica, constitutiva. Por eso el concepto clave es el de trabajo vivo, porque en él se mantiene unido el trabajo y la acción.

3. La cítica "postoperaista": el cuestionamiento de la dicotomía entre "acción comunicativa" y acción instrumental habermasiana

Los autores postoperaistas reconocen en Habermas el gesto filosófico de querer integrar el lenguaje y la comunicación intersubjetiva con la ética como alternativa a la racionalización capitalista; igualmente, reconocen en Habermas su utilización del lenguaje y de la comunicación para definir las potencialidades

${ }^{25}$ Krahl, H.J., Costituzione e lotta di clase, Milán: Jaka Book, 1973. 
de perfeccionamiento de la democracia, situando las principales cuestiones políticas de la democracia en el plano del lenguaje.

En términos generales, podemos decir que las críticas postoperaistas a los planteamientos habermasianos, tanto de Negri, Virno y Marazzi, señalan cómo las nuevas formas de producción postfordistas hacen que la distinción entre acción comunicativa y acción instrumental carezca de sentido; ponen en cuestión la naturaleza que Habermas otorga a la esfera pública, a la escisión y separación entre la esfera pública como lugar de lo político frente al espacio de lo privado y personal; y analizan en qué medida el potencial hermenéutico de la acción comunicativa queda anulado por el desplazamiento del problema del nivel ontológico al ético, bloqueando así la creatividad del proceso de subjetivación al haber definido previamente los trascendentales formales.

Tal y como hemos analizado, para Habermas la comunicación es un espacio de diálogo abierto y una fuerza para la democracia, mientras que la economía y el lugar de trabajo se hallan sujetos a una lógica instrumental que encuentra su razón en la racionalidad capitalista. Las dos formas de acción descritas por Habermas constituyen un marco trascendental en cuyo interior se organiza la experiencia a priori de toda la realidad. El ámbito de la "acción instrumental", que incorpora la categoría de trabajo, sigue la lógica de medios-fines; la acción comunicativa, por el contrario, se sitúa en la esfera de la interacción, y es referida a sujetos hablantes. La autonomía y la libertad respecto a la irracionalidad individual y la injusticia social es el objetivo de todo conocimiento referente al interés emancipatorio ${ }^{26}$, y se arraiga en el lenguaje, donde se dan las condiciones de posibilidad de la razón capaz de introducir un orden en la comunicación.

Por ello, lo que Habermas denomina el sistema social (la economía, la administración), está guiado por la racionalidad instrumental; los espacios en los que se extiende el mundo de la vida, en cambio, están guiados por la racionalidad comunicativa. Así, sistema social y mundo de la vida hacen referencia a dos pautas de racionalización diferenciadas.

Pues bien, es precisamente esta separación o dicotomía entre las dos esferas la que se ha visto desequilibrada y trastocada: "la acción comunicativa ha sido mercantilizada: el trabajo es interacción, la comunicación es trabajo, el lenguaje es rendimiento, la información es productividad, los conceptos

${ }^{26}$ Habermas, J., Conocimiento e interés. 
son gestión"27. La única racionalidad concebible es la racionalidad económica para la cual solo existe un modo de acción: la acción instrumental. Este es el obstáculo que presenta la distinción habermasiana entre acción comunicativa y acción instrumental para los autores postoperaistas.

Virno sostiene que el principal aspecto de la sociedad globalizada actual, aquel del cual derivarán todos los demás, es la simbiosis entre lenguaje y trabajo. La principal novedad de los modos de producción postfordistas consiste en haber puesto el lenguaje a trabajar; el capitalismo contemporáneo ha capturado el uso del lenguaje, apropiándose de la capacidad de hablar, junto con otras capacidades genéricas.

En el postfordismo, el trabajo ha incorporado elementos propios de la experiencia política. Virno ${ }^{28}$ analiza cómo se han disuelto los límites entre la pura actividad intelectual, la acción politica y el trabajo. En particular, se centra en sostener que el trabajo postfordista ha absorbido muchas de las características que antes distinguían a la acción política. En el trabajo se manifiesta hoy la exposición a los ojos de los otros, la relación con la presencia de los demás o la familiaridad con la contingencia, lo imprevisto, lo posible, la capacidad de empezar algo nuevo o la elección entre posibilidades alternativas. Al hecho de que el proceso laboral subsuma aquello que previamente garantizaba la acción pública, a la subsunción de la agencia política en los procesos de trabajo, lo denomina Virno virtuosismo, para señalar esta superposición entre trabajo y política $^{29}$. Lo político tiene lugar tanto en la esfera pública como en los ámbitos de la producción.

Si el trabajo ha perdido su especificidad, entonces se derrumba la línea que separaba el trabajo del resto de la experiencia, "si todo es trabajo, se podría decir también que ya nada lo es"30. Virno sostiene que el trabajo postfordista es interacción, "el proceso laboral ya no es más taciturno sino locuaz"31. Es decir, el actuar comunicativo habermasiano no puede pertenecer a un terreno exclusivo de relaciones politicas o éticas, sino que se ha insertado en el ámbito

\footnotetext{
27 Ayestarán, I., "Capitalismo cognitivo en la economía high tech y low cost: de la ética hacker a la wikinomia”, en: Argumentos de Razón Técnica, 10 (2007), p. 93.

${ }^{28}$ Virno, P., Gramática de la multitud. Para un análisis de las formas de vida contemporánea.

${ }^{29}$ Virno, P., Virtuosismo y revolución. La acción politica en la época del desencanto.

${ }^{30}$ Virno, P. Cuando el verbo se hace carne. Lenguaje y naturaleza humana, Madrid: Traficantes de sueños, 2005, p. 26.

${ }^{31}$ Virno, P., Gramática de la multitud. Para un análisis de las formas de vida contemporánea, p. 113.
} 
de la reproducción material de la vida. La acción instrumental y la acción comunicativa están entrelazadas.

Por su parte, Marazzi ${ }^{32}$ señala que el problema de la teoría de la acción comunicativa radica en que está pensada desde la forma política de la democracia heredada del fordismo. En cambio, en la producción postfordista, es dificil poder encontrar la pretendida mediación supraindividual habermasiana, ese plano donde poder establecer compromisos y consensos duraderos, dado que ha estallado la división entre acción instrumental y acción comunicativa. El problema del planteamiento habermasiano es que "detiene su análisis en el umbral de la acción productiva y se priva, así, de la posibilidad de comprender las transformaciones político-institucionales" ${ }^{33}$, esto es, no es capaz de atender a las transformaciones de los presupuestos que se derivan de los nuevos modos de producción.

La segunda crítica que introduce Marazzi tiene que ver con la concepción habermasiana del lenguaje como vehículo de la socialización. Pensar así el lenguaje lo considera un enfoque insuficiente en la medida en que conduce a un voluntarismo que se traduce en ingenuidad política. Pensar que la acción comunicativa se construye sobre la premisa de que la dimensión discursiva de las relaciones entre sujetos constituye un hecho objetivo porque es socialmente compartido, solo puede ser válido en el interior de una comunidad homogénea como, por ejemplo, "una comunidad de profesores académicos que trabajan en el mismo campo disciplinar o bien una clase política que ha desarrollado con el tiempo una comunicación habitual que le es propia" ${ }^{34}$. Una crítica similar la formula Emanuele Severino, para quien la teoría de la acción comunicativa de Habermas, en su pretensión de conseguir un alcance general, "no es en realidad más que una robinsonada trasladada al plano de la lingüística... De hecho, Robinson habla a Viernes en inglés y ni siquiera se preocupa de saber si su esclavo hablaba otra lengua antes de encontrarse con su amo"35.

En el caso de Negri, esa reelaboración habermasiana de la relación de lo público con lo privado de manera trascendente choca con su concepción de lo común, que parte del rechazo de todas las pretendidas divisiones originarias entre lo público y lo privado. El concepto multitud de Negri responde, justamente,

\footnotetext{
${ }^{32}$ Marazzi, Ch., El sitio de los calcetines. El giro lingüistico de la economía y sus efectos sobre la politica, p. 28.

${ }^{33}$ Ibid., p. 27.

${ }^{34}$ Ibid.

${ }^{35}$ Severino, E., La tendencia fundamental de nuestro tiempo, Pamplona: Pamiela, 1991, p. 58.
} 
a la pretensión de elaborar de manera abierta el concepto de lo común, como conjunto de singularidades, de un tejido cooperativo que entrelaza una infinidad de actividades singulares ${ }^{36}$. De aquí se derivan dos consecuencias:

En primer lugar, Negri señala un eco racionalista y moralista en este intento de separar el mundo de la comunicación libre del sistema de instrumentalización y dominación. Ahí es donde la concepción habermasiana de la comunicación ética en una esfera pública democrática se evidencia para Negri totalmente utópica e irrealizable, porque no podemos aislarnos, ni aislar nuestras comunicaciones y relaciones, al margen de la instrumentalidad del capital y de los medios de comunicación. El énfasis habermasiano sobre la independencia y la creatividad de la comunicación es utópico, no porque la comunicación en cuanto tal, como valor, sea una utopía inalcanzable, sino en la medida en que Habermas no atienden al sustrato material en el que se inscribe hoy la comunicación: la naturaleza sustancial de la producción del obrero social ${ }^{37}$.

Habermas no habría logrado entender que ya estamos todos dentro de esa instrumentalidad del capital, insertos en ella. Es por esto que "la redención ética, si es que esta puede tener lugar, habrá que construirla dentro del sistema"38. Negri está convencido de que la producción comunicativa y la construcción de la legitimación del Imperio marchan juntas y no pueden separarse ${ }^{39}$.

En segundo lugar, el proyecto de Habermas, basado en un esquema formal trascendental, es visto por Negri como tendente siempre a mantener un orden social. En la medida en que las ideas habermasianas de razón y acción comunicativa llegan a definir un proceso que media constantemente toda la realidad social, ello comporta la aceptación e incluso el refuerzo de las condiciones dadas del orden social existente ${ }^{40}$.

Resumiendo, crítica postoperaista señala que la oposición y dicotomía establecida por Habermas entre acción instrumental y acción comunicativa quedaría impugnada por el modo de producción postfordista. El trabajo postfordista es un trabajo fundamentalmente comunicativo, tiene un carácter

\footnotetext{
${ }^{36}$ Negri, A., La fábrica de porcelana. Una nueva gramática de la política, Barcelona: Paidós, 2006, pp. 91-92.

${ }^{37}$ Negri, A. Fin de siglo, pp. 115-116.

${ }^{38}$ Hardt, M. y A. Negri, Multitud. Guerra y democracia en la era del Imperio, Barcelona: Debate, 2004, p. 300.

${ }^{39}$ Hardt, M. y A. Negri, Imperio, Barcelona: Debate, 2000.

${ }^{40}$ Hardt, M. y A. Negri, Commonwealth. El proyecto de una revolución del común, Madrid: Akal, 2001 , p. 34.
} 
esencialmente comunicativo y social, necesita de un alto grado de capacidades lingüísticas para poder ser productivo. Habermas pretendía que la acción comunicativa fuese un lugar de protección sobre la tendencia colonizadora de la producción capitalista. El problema es que la colonización sobre la acción comunicativa ya ha tenido lugar.

Si en el centro de las transformaciones del trabajo postfordista se encuentra la entrada del lenguaje en la esfera de la producción, entonces la distinción habermasiana entre acción comunicativa y esfera de la producción es un obstáculo en la medida en que la acción comunicativa ha sido privatizada, ha sido convertida en una nueva esfera de explotación. La producción postfordista rompe la distinción entre tiempo de trabajo y tiempo de vida, por lo que los procesos de explotación no están ya circunscritos a la esfera de la producción. El proceso de subjetivación no se basa, tal como lo presenta Habermas, en lo trascendental de la comunicación, sino en un proceso inmanente de constitución. No es posible determinar una exterioridad sociológica a las relaciones capitalistas de producción.

\section{La dicotomía entre trabajo material e inmaterial: un nuevo plano de inmanencia temporal}

A partir de lo sostenido hasta ahora, podría pensarse que las reflexiones postoperaistas proponen una dicotomía entre trabajo inmaterial y trabajo material, inscribiendo cada uno en un espacio propio, al modo que Habermas separa acción comunicativa y acción instrumental. Pero la división entre trabajo material e inmaterial no permite trazar un mapa de la producción, a partir de una geografia y de nítidos y claros contornos en el que lo material e inmaterial poseyeran, cada uno, un locus determinado. Es justo lo contrario: el postoperaismo trata de establecer las posibles conexiones entre lo material e inmaterial, evitando así una separación entre ambas.

En este sentido, nos parece que Sean Sayer ${ }^{41}$ parte de una comprensión errónea del trabajo inmaterial en Negri y Hardt. Para él, los autores de la 260 trilogia Imperio, Multitud y Commonwealth tienden a reproducir un dualismo entre trabajo material y trabajo inmaterial, reproduciendo un nuevo dualismo al modo habermasiano. Sayer sostiene que Hardt y Negri obvian que todo el trabajo humano es social y que necesariamente implica un elemento comuni-

\footnotetext{
${ }^{41}$ Sayer, S., "The Concept of Labor: Marx and His Critics", en: Science \& Society, v. LXXI, 4 (2007), pp. 431-454.
} 
cativo; e, igualmente, obvian que todas las relaciones sociales humanas tienen sus raíces en un trabajo material.

En lo que sigue, trataremos de argumentar que la producción inmaterial, tal como es conceptualizada por los autores postoperaistas, no se define únicamente por oposición a la producción material, fisica y tangible fordista, sino que es intrínsecamente inmaterial en la medida en que se nutre y se fundamenta sobre la práctica del lenguaje en tanto elemento constituyente del conjunto del proceso económico. De manera tal que no existe tal reproducción del dualismo habermasiano.

Sería un error inscribir el devenir lingüístico de la producción que analiza el postoperaismo en una suerte de genealogía que concibiese el desarrollo del capitalismo en un sentido puramente lineal y progresivo. La historia no es un proceso lineal, sino que procede por superposiciones e hibridaciones. Desde esta perspectiva, el postfordismo no es un nuevo estadio de desarrollo, según la imagen historicista clásica. Antes bien, en el postfordismo, diferentes modelos productivos continúan coexistiendo y articulándose; no existen, por así decir, medios de producción puros, nunca la irrupción de un nuevo modo de producción hace desaparecer a los anteriores.

Siguiendo esta línea, Virno ${ }^{42}$ sostiene que el postfordismo reedita todo el pasado de la historia del trabajo, desde las islas de obrero masa a enclaves de obreros profesionales. Los modelos de producción que han tenido lugar a lo largo de la historia se representan hoy de forma sincrónica, "casi del mismo modo que una Exposición Universal". A diferencia del modo producción fordista, la actual organización del trabajo es siempre "en manchas de leopardo"43. Citando al Marx de los Grundrisse, podríamos definir el postfordismo como "una iluminación general que incorpora en sí todos los colores, modificando sus particularidades; es la atmósfera particular que determina todo lo que envuelve".

En ese sentido, las innovaciones tecnológicas no son universales: más que determinar un modelo productivo único y conductor, ellas mantienen con vida modelos diferenciados, resucitándolos de sus anacronismos y superaciones. En efecto, los diferentes modos de producción que se han sucedido a lo largo de la historia no pueden ser definidos a partir de un único modelo de producción al que asociarle un único modelo de trabajo. Desde el surgimiento del capitalismo, siempre han coexistido y convivido diferentes modos de producción. La aparición de nuevas formas de producción no implica la desaparición de las

\footnotetext{
${ }^{42}$ Virno, P., Virtuosismo y revolución. La acción politica en la época del desencanto.

43 Ibid., p. 111.
} 
anteriores: siempre existen residuos de lo previo. Atender a las actualizaciones de lo antiguo podría ser el mecanismo para una genealogía de los modos de producción postfordistas. El postfordismo es, pues, un tiempo acumulado, un nuevo plano de inmanencia temporal.

¿Qué lugar ocupa, entonces, el postfordismo en tanto modo de producción integrado? ¿Qué añade el prefijo "-post”? Antonio Negri y Michael Hardt ${ }^{44}$ sostienen que el modo de producción postfordista es el modo de producción hegemónico en términos cualitativos, el que marca la tendencia. Esta idea está en consonancia con el principio articulado por Marx en el primer el capítulo "Maquinaria y gran industria" del libro I de El Capital, donde considera que en cada una de las fases del desarrollo capitalista la forma dominante de trabajo asimilará hegemónicamente en sí misma a todas las demás.

Así, durante los siglos XIX y XX, el trabajo fabril fue hegemónico en la economía global, aun siendo minoritario en términos cuantitativos respecto a otras formas de producción -como la agricultura o la minería-. La industria era hegemónica en el sentido de que ejercía una atracción centrípeta sobre otras formas de producción: la agricultura o la minería, por ejemplo, se vieron obligadas a industrializarse. Los procesos de modernización e industrialización transformaron y redefinieron todos los elementos del plano social: cuando la agricultura fue modernizada como industria, la granja se volvió progresivamente una fábrica e incorporó toda la disciplina fabril, la tecnología y las relaciones salariales.

Cuando Negri y Hardt postulan que el trabajo inmaterial tiende a asumir la posición hegemónica, no están afirmando que la mayoría de los trabajadores se dediquen fundamentalmente a producir bienes inmateriales. Antes bien, reconocen que el trabajo inmaterial es una parte minoritaria del trabajo global y que, además, este se concentra en determinadas partes del mundo. Lo que sostienen es que el trabajo inmaterial se encuentra ahora en la situación en la que se encontraba el trabajo industrial hace más de un siglo, cuando representaba una pequeña fracción de la producción global y se hallaba concentrado en una parte reducida del mundo -cuando Marx hablaba en su tiempo del predominio de la producción industrial en Inglaterra, solo una minoría trabajaba de hecho en las fábricas, a pesar de lo cual ejerció su hegemonía sobre todas las demás formas de producción-. De la misma forma que en el siglo XIX se produjo una industrialización de todas las formas de trabajo y de la propia

${ }^{44}$ Hardt, M. y A. Negri. Multitud. Guerra y democracia en la era del Imperio, p. 136. 
sociedad, asistimos hoy a esa misma transformación: el trabajo y la sociedad se informatizan, se vuelven comunicativos, lingüísticos.

Así pues, el trabajo hoy está articulado en, y bajo el mando de, procesos de valorización y acumulación de capital que funcionan según lógicas diversas de las esencialmente industriales. Estas últimas ya no constituyen el centro de la valorización capitalista, ni el modelo de subjetivación política del conjunto de las fuerzas sociales. Pero ello no quiere decir, insistimos, que el trabajo inmaterial haya desaparecido. El postfordismo no ha eliminado la producción industrial, sino que la ha subsumido e integrado en una nueva lógica de valorización del capital.

No han desaparecido, pues, ni el trabajo mercantil ni otras formas de prestación laboral, ni tan siquiera son cuantitativamente irrelevantes; pero la producción inmaterial es el sector con la tasa de productividad más alta, el sector más dinámico y el que funciona como elemento de transformación tendencial.

Hoy, distintos modos de producción conviven entre sí. Estos diferentes modos de producción participan de un mismo flujo global de intercambios lingüísticos, comunicacionales, productivos, afectivos y culturales. Vemos, pues, que cada régimen de producción se caracteriza por varias formas comunes e isomorfismos que estructuran diversos elementos de la realidad social. Este es el modo propiamente postfordista de actualización de lo viejo, la forma de hacer visible la simultaneidad de lo asincrónico.

Así pues, la distinción postoperaista entre trabajo material y trabajo inmaterial no reproduce el dualismo habermasiano entre acción comunicativa y acción instrumental. La razón de ello radica en que el postoperaismo trata de leer las transformaciones postfordistas siendo fieles a la lectura del trabajo vivo en Marx como principio productivo inmanente y como fuerza ontológica. $\mathrm{O}$, dicho en otros términos, quieren mantener vigente el potencial hermenéutico del general intellect marxiano, potencial que es anulado en el planteamiento habermasiano, en la medida en que la dualidad entre las dos acciones comporta el desplazamiento del problema del nivel ontológico al ético.

Recibido: $10 / 12 / 2020$

Aceptado: 12/07/2021 


\section{Bibliografia}

Ayestarán, I., "Capitalismo cognitivo en la economía high tech y low cost: de la ética hacker a la wikinomía”, en: Argumentos de Razón Técnica, 10 (2007).

Habermas, J., Teoria de la acción comunicativa, Barcelona: Taurus. 1981.

Habermas, J., La reconstrucción del materialismo histórico, Barcelona: Taurus, 1992.

Habermas, J., Conocimiento en interés, Valencia: Universitat de Valencia, 1995.

Habermas, J., Debate sobre el liberalismo político, Barcelona: Paidós, 1998.

Habermas, J., Facticidad y Validez, Barcelona: Trotta, 1998.

Habermas, J., La ética del discurso y la cuestión de la verdad, Barcelona: Paidós, 2003.

Habermas, J., Historia y estructura de la vida pública, Barcelona: Gustavo Gili, 2004.

Habermas, J., Normas y valores, Barcelona: Trotta, 2008.

Habermas, J., Sobre la verdad: ¿validez universal o justificación?, Buenos Aires: Amorrortu, 2008.

Habermas, J., Ciencia y técnica como “ideología”, Barcelona: Tecnos, 2009.

Hardt, M.y A. Negri, Imperio, Barcelona: Debate, 2000.

Hardt, M. y A. Negri, Commonwealth. El proyecto de una revolución del común, Madrid: Akal, 2001.

Hardt, M. y A. Negri, Multitud. Guerra y democracia en la era del Imperio, Barcelona: Debate, 2004.

Krahl, H.J., Costituzione e lotta di clase, Milán: Jaka Book, 1973.

Lazzarato, M. y otros, "Le travail: un nouveau débat pour de vieilles alternatives", en: Futur Antérieur, 35-36 (1996/2).

Marazzi, Ch., El sitio de los calcetines. El giro lingüístico de la economía y sus efectos sobre la política, Madrid: Akal, 2003.

Negri, A., Del obrero-masa al obrero social. Entrevista sobre el obrerismo a cargo de Paolo Pozzi y Roberta Tommasini, Barcelona: Anagrama, 1980.

Negri, A., Fin de siglo, Barcelona: Paidós, 1992.

Negri, A., Kairos, Alma, Venus, Mutitudo, Roma: Manifestolibri, 2000. https://doi. org/10.5840/gfpj200022115

Negri, A., Marx más allá de Marx. Cuaderno de trabajo sobre los Grundrisse, Madrid: Akal, 2001.

Negri, A., La fábrica de porcelana. Una nueva gramática de la política, Barcelona: Paidós, 2006.

Revelli, M., Más allá del siglo XX. La política, las ideologías y las asechanzas del trabajo, Barcelona: El Viejo Topo, 2002.

Sayer, S., "The Concept of Labor: Marx and His Critics", en: Science \& Society, v. LXXI, 264 (2007), pp. 431-454. https://doi.org/10.1521/siso.2007.71.4.431

Severino, E., La tendencia fundamental de nuestro tiempo, Pamplona: Pamiela, 1991.

Virno, P., Gramática de la multitud. Para un análisis de las formas de vida contemporánea, Madrid: Traficantes de sueños, 2003.

Virno, P., Virtuosismo y revolución. La acción política en la época del desencanto, Madrid: Traficantes de sueños, 2003.

Virno, P. Cuando el verbo se hace carne. Lenguaje y naturaleza humana, Madrid: Traficantes de sueños, 2005. 